\title{
EVALUATION OF ION RELEASE, APATITE FORMATION AND TOOTH-RESTORATION INTERFACE OF BIOACTIVE RESIN COMPOSITE VERSUS CONVENTIONAL RESIN COMPOSITE (AN IN VITRO STUDY)
}

\author{
Mariam M. Fahmy*, Taheya A. Moussa** \\ and Rasha M. Abdelraouf ***
}

\begin{abstract}
Aim: Evaluation of ion release, apatite formation and tooth-restoration interface of a commercial bioactive restoration compared to the conventional one.

Methodology: Two types of commercially available composite restorations; a bioactive type (Filtek $^{\mathrm{TM}}$ Z350-XT, 3M ESPE, St. Paul, MN, USA) and a conventional one as a control (ACTIVA, BioACTIVE, Pulpdent, USA) was tested through this study. Calcium and phosphorous ions release were analyzed via Inductively coupled plasma. Apatite formation was tested using scanning electron microscope (SEM) and Energy dispersive x-ray spectroscopy (EDX) after discs immersion in phosphate buffer saline for 14 days. Calcium/Phosphorous ratio was also calculated. The gap distance at the interface was measured using SEM, after immersion of buccolingual sections of Class V cavities filled with the restorations, in phosphate buffer saline for 14 days.Z
\end{abstract}

Results: Results revealed insignificant difference regarding mean $\mathrm{Ca}$ ions values while for the $\mathrm{P}$ ion release mean values a significant difference was found between the tested materials. While SEM micrographs for ACTIVA ${ }^{\mathrm{TM}}$ bioactive restorative discs surfaces showed white globules with $\mathrm{Ca} / \mathrm{P}$ ratio=1.7. Gaps were detected at the interface between the teeth structure and both tested materials with insignificant differences between them. On the other hand, crystal-like structure was detected at the gaps borders between ACTIVA ${ }^{\mathrm{TM}}$ bioactive restorative and teeth structure.

Conclusions: ACTIVA bioactive restorative material seems promising regarding ions release and apatite formation yet closing the gap at the interface may need long term inspection duration.

KEYWORDS: Bioactive materials, ACTIVA, Ion release, Apatite, restorative materials.

\footnotetext{
* Demonstrator, Biomaterials Department, Faculty of Dentistry, Cairo, British University in Egypt

** Professor, Biomaterials Department, Faculty of Dentistry, Cairo University, Cairo, Egypt

*** Associate Professor, Biomaterials Department, Faculty of Dentistry, Cairo University, Cairo, Egypt
} 


\section{INTRODUCTION}

Traditionally, the main scope for operative dentistry were the removal of caries and then subsequent tooth restoration with an appropriate material to simulate the natural tooth structure. Consequently, the restoration must demonstrate satisfactory attributes at the tooth-material interface to form a high-quality seal that resist oral fluids (Owens et al., 2018).

Direct esthetic restorative materials are the materials of choice for more than 40 years due to its improved esthetics and the conservative preparation techniques. However, previously the literature reports highlighted that the resinous restorative materials facilitate cariogenic biofilm growth (Spencer et al., 2014). Recurrent caries develops at the tooth-restoration interface resulting in restoration failure. Therefore, there is a new approach to develop aesthetic restorative materials that can inhibit recurrent caries. The capability of the resin composite restoration to positively affect its biological surroundings is an avenue for improving the longevity and clinical service inside the mouth (Vallittu et al., 2018).

Advances in dental restorative materials have progressed by incorporation of bioactive components for caries prevention, tooth remineralization, and restoration. The materials which are termed "bioactive" or "biomineralizing" are limited only to the scientifically proven dental materials that release substantial quantities of ions 'calcium, phosphate, fluoride' that are responsible mainly for increasing the tooth structure resistance to acid attack and formation of apatite layer resulting in a specific biomineralization in the tooth structure clinical environment (Odermatt et al., 2020).
Several experimental studies incorporated inorganic calcium phosphate (Ca-P) bioactive fillers into restorative materials to induce anti-caries activities by releasing sufficient levels of ions that form a stable apatite layer. Yet, adjusting the Ca-P formulations was challenging to avoid deleterious effects on the physical and mechanical properties of the restorative materials (Balhaddad et al., 2019).

A launched restorative material (ACTIVA $^{\mathrm{TM}}$ bioactive restorative material, Pulpdent, USA) is a claimed bioactive restorative material, reviving hydroxyapatite layer formation and natural remineralization at the tooth-restoration interface by significant release and recharge of calcium, phosphorus and fluoride ions (Benetti et al., 2019). ACTIVA $^{\mathrm{TM}}$ bioactive restoration was marketed as a pioneer restorative material with a patented hydrophilic ionic resin matrix and bioactive ionic glass fillers that facilitates calcium, phosphate, and fluoride ions diffusion which in turn react to oral $\mathrm{pH}$ changes. The manufacturer claimed that the material combines between the properties of a resin modified glass ionomer with improved resilience and physical properties of the resin composite (Owens et al., 2018).

Therefore, this study was designed to evaluate the ions release, apatite formation and toothrestoration interface of this recently introduced bioactive restorative material (ACTIVA bioactive) versus the conventional resin composite (Filtek 3M Z350).

\section{MATERIAL AND METHODS}

\section{Material}

Commercial materials used in this study are represented in table (1). 
TABLE (1): Materials used, commercial names, lot numbers according to the manufacturers, their composition, and manufacturer:

\begin{tabular}{|c|c|c|c|c|}
\hline Material & $\begin{array}{c}\text { Commercial } \\
\text { names }\end{array}$ & Lot no. & Main Composition & Manufacturer \\
\hline $\begin{array}{l}\text { Bioactive } \\
\text { restorative } \\
\text { material }\end{array}$ & $\begin{array}{l}\text { ACTIVA }^{\mathrm{TM}} \\
\text { bioactive } \\
\text { restorative } \\
\text { material }\end{array}$ & 180501 & $\begin{array}{l}\text { Patented bioactive ionic resin. } \\
\text { Patented rubberized resin. } \\
\text { Bioactive ionic glass. } \\
\text { Mix of methacrylates and diurethane with modified } \\
\text { polyacrylic acid ( } 44.6 \%) \text {; reactive glass filler } \\
\text { ( } 21.8 \text { wt. } \%) \text {; inorganic filler (56 wt. \%). } \\
\text { Contain no bisphenol A, no bis-GMA, no BPA } \\
\text { derivatives. } \\
\text { Amorphous silica }(6.7 \%) \text {, sodium fluoride }(0.75 \%) \text {. }\end{array}$ & $\begin{array}{l}\text { Pulpdent }^{\circledR}, \\
\text { Watertown, } \\
\text { USA }\end{array}$ \\
\hline $\begin{array}{l}\text { Conventional } \\
\text { resin } \\
\text { composite }\end{array}$ & $\begin{array}{l}\text { Filtek }^{\mathrm{TM}} \text { Z350- } \\
\text { XT }\end{array}$ & NA11276 & $\begin{array}{l}\text { Bis-GMA(bisphenol A glycol } \\
\text { dimethacrylate), UDMA(urethane } \\
\text { dimethacrylate), PEGDMA(poly ethylene glycol) } \\
\text { dimethacrylate, TEGDMA (triethylene glycol } \\
\text { dimethacrylate), Bis-EMA resins(bisphenol A } \\
\text { ethoxylated dimethacrylate), } 20 \mathrm{~nm} \text { silica filler, 4-11 } \\
\text { nm zirconia filler, and aggregated zirconia/silica } \\
\text { cluster filler } 72.5 \text { wt. \%. }\end{array}$ & $\begin{array}{l}3 \mathrm{M} \mathrm{ESPE}^{\circledR}, \text { St. } \\
\text { Paul, MN, USA }\end{array}$ \\
\hline Bonding agent & Single Bond & N796659 & $\begin{array}{l}\text { BIS-GMA, dimethacrylate resins, polyalkenoic acid } \\
\text { copolymer, HEMA (2-hydroxyethyl methacrylate), } \\
\text { silane, ethanol, water, } 10 \mathrm{vol} \% \text { silica nanofillers }\end{array}$ & $\begin{array}{l}3 \mathrm{M} \mathrm{ESPE}^{\circledR}, \text { St. } \\
\text { Paul, MN, USA }\end{array}$ \\
\hline Etching gel & FineEtch & FE19222 & 37\% Phosphoric acid & SpiDent, Korea \\
\hline
\end{tabular}

\section{Methods}

\section{Specimens Grouping and Test Design}

Twenty-disc shaped specimens were prepared in this study for ion release and apatite formation tests. While for tooth-restoration interface examination, ten resin composite restorations were used to fill ten prepared class $\mathrm{V}$ cavities in the buccal and lingual surfaces of five freshly extracted sound human molars.

Specimens and restorations were divided according to the type of the material used into two groups; Group I: Conventional resin composite as a control group and Group II: Bioactive restorative material the intervention group, both with the shade A3. The number of specimens were determined according to the sample size calculator: Power and Sample Size Calculation Software Version 3.1.2 (Vanderbilt University, Nashville, Tennessee, USA).

\section{Preparation of resin composite discs for ion re- lease and apatite formation tests}

For the ion release and apatite formation tests, Twenty-disc shaped specimens $(10 \mathrm{~mm}$ diameter $\mathrm{x} 1 \mathrm{~mm}$ thickness) were prepared from the resin composites ( $n=5$ /group) using a specially designed holed metallic split Teflon mold. The conventional resin composite was presented as a syringe with one compartment, while the bioactive one, as an 
automix syringe with two compartments containing the two pastes, mixed by co-extrusion through a spiral nozzle.

To prepare each specimen, the Teflon mold was placed above a glass slab with a clear Mylar celluloid strip (Crosstex, USA) and the uncured resin composite was applied in this mold. A dental floss (Oral-B, USA) was inserted inside the soft material with $5 \mathrm{~cm}$ projecting from the mold's ring for handling. Then, another celluloid strip and glass slab were placed above the paste filling the mold. A $200 \mathrm{gm}$ weight was placed to release any air bubbles and remove excess material. The specimens are then light cured for 20 seconds using LED unit (Bluephase G2, Ivoclar-Vivadent Inc., Schaan, Liechtenstein) with distance between the light curing unit tip and restoration's surface of $1 \mathrm{~mm}$.

\section{Ion Release Test}

Five-disc shaped specimens from each material were used for assessment of calcium (Ca) and phosphorous (P) ion release. Each disc was immersed in $5 \mathrm{ml}$. distilled water (Classikool, UK) in a lidded plastic test tubes (Celistar tubes, Greiner Bio-one $\mathrm{GmbH}$, Germany), for 14 days at $37^{\circ} \mathrm{C}$ in an incubator (Binder BD56, Germany) (Alshammary, 2019). The aliquots in both materials were analyzed for $\mathrm{Ca}$ and $\mathrm{P}$ release via Inductively coupled plasma (ICP) Spectrometry (Ultima 2 JY Plasma, Japan). The released ions were represented in part per million (ppm) concentration units.

\section{Examination of Apatite Phase Formation}

Five discs from each material ( $\mathrm{n}=5 /$ group) were used for the examination of apatite phase formation. Each disc was soaked in $5 \mathrm{ml}$. Phosphate Buffer Saline (PBS, Biodiagnostics, Dokki, Egypt) with $\mathrm{pH} 7.4$ and incubated at $37^{\circ} \mathrm{C}$ for 14 days with changing each solution every 2 days. After storage, the specimens were thoroughly rinsed with deionized water for 3 minutes and blotted dry with absorbent paper before the analysis (Profeta et al., 2012) (Jang et al., 2018) (Badahman, 2019).
The surfaces of the specimens were observed and analyzed using Scanning electron microscope (SEM) and Energy dispersive $\mathrm{x}$-ray (EDX) spectroscopy (FEI Inspect ${ }^{\mathrm{TM}}$ S50, USA). Calcium/Phosphorous ratio was calculated.

\section{Tooth-restoration interface examination}

\section{Teeth selection, cavity preparation and restorations}

Five freshly extracted sound permanent human molars were used. All teeth were cleaned of debris. All calculus and soft deposits were removed from teeth with hand scaler (Scaler 10A, NOVA instruments Ltd, BerkShire, UK). The teeth were then cleaned using a fluoride free pumice $\left(\mathrm{NADA}^{\mathrm{TM}}\right.$, PREVENTECH, USA) and low speed handpiece (NSK NAC-Y, Japan) then rinsed and stored in distilled water until used.

Each tooth was embedded in a pink wax block (Cavex, Holland, Netherlands) to facilitate the handling during cavity preparation and restoration processes. Class V cavities were prepared on the buccal and the lingual surfaces of each tooth (total number of cavities $=10$ ). Class $\mathrm{V}$ cavities preparation were done with a high-speed hand piece under water coolant using cylindrical diamond burs (Kerr BluWhite Diamond ${ }^{\mathrm{TM}}$, Switzerland).

The class $\mathrm{V}$ cavities were prepared with dimensions; $3 \mathrm{~mm}$ (mesiodistal), $2 \mathrm{~mm}$ (occlusogingival) and $1.5 \mathrm{~mm}$ depth with the preparation extending $1 \mathrm{~mm}$ above the cementoenamel junction. To standardize the cavity depth, the bur was marked after $1.5 \mathrm{~mm}$ with nail varnish. Each cavity was then measured with a periodontal probe to maintain uniformity. All prepared teeth were thoroughly rinsed with water and gently dried then restored with the tested restorative materials.

In each tooth, one cavity was restored by the conventional resin composite (Group I), while the other cavity in the same tooth was restored by bioactive restorative material (Group II). 
Acid etching using 37\% phosphoric acid (FineEtch, SpiDent, Korea) were applied for both materials for 15 seconds according to the manufacturers' instructions, then rinsed, and air dried gently for two seconds to remove the excess water leaving a wet reflective surface. According to the manufacturers' instructions, the bonding agent was a mandatory step in both groups. For each cavity two consecutive coats of bonding-agent (Single-Bond, 3M-ESPE, Germany) was applied using a brush (EvoDent, Hong Kong, China), then air dried for two seconds and light cured for 20 seconds using the light curing unit.

Finally, packing of the restorative materials into the cavities were done according to the manufacturers' instructions. For 'ACTIVA ${ }^{\mathrm{TM}}$ bioactive restorative material, the mixing tip was placed on the restorative syringe, syringe inserted into ACTIVA $^{\mathrm{TM}}$ bioactive restorative material spenser and snapped into place using firm pressure. Two $\mathrm{mm}$ of the restorative material was dispensed onto a mixing pad then discarded to check the even mix of the base and catalyst. The restoration was then dispensed directly into the cavity from the tip using slow steady pressure, starting dispensing at the deepest portion of the cavity, and keeping the tip close to the cavity floor. The tip was gradually withdrawn as the cavity was filled, and light cured for 40 seconds.

For the conventional resin composite (Filtek 3M Z350), application of the material was performed using composite applicator (Hu-Friedy Mfg. Co., Chicago, Ill, USA). Restorations were light cured for 40 seconds and finished using fine needle and flame-shaped diamond burs (010, Diaswiss, Nyon, Swiss). Polishing discs (Sof- Lex ${ }^{\mathrm{TM}}, 3 \mathrm{M}$ ESPE, USA) were used to obtain the final finish.

\section{Teeth Sectioning}

The teeth were sectioned under water lubrication using a circular diamond saw (Isomet, Buehler Ltd., Lake Bluff, IL, USA) fixed in straight hand piece low speed (NSK EX-203C, Japan). The sectioning was done in a buccolingual direction through the buccal and lingual restorations across the adhesive interface of each tooth, dividing the tooth into two halves using one half of each tooth for analysis (YliUrpo et al., 2005) figure (1).

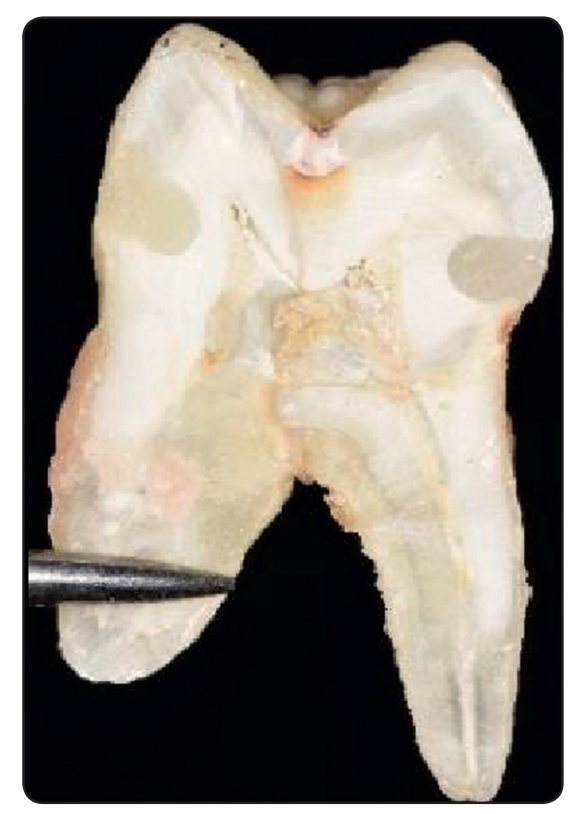

Fig. (1) Sectioned tooth after restoring the buccal and lingual cavities.

\section{Interfacial SEM examination}

The sectioned teeth were immersed in the phosphate buffer saline and incubated at $37^{\circ} \mathrm{C}$ for 14 days (Profeta et al., 2012) (Jang et al., 2018). The teeth-restorations interfaces were examined and the gap distance at the interface was measured using scanning electron microscope (FEI Inspect ${ }^{\mathrm{TM}}$ S50, USA) with an accelerating voltage $30 \mathrm{~K} . \mathrm{V}$ at magnification $1000 x$.

\section{Statistical analysis}

The statistical analysis was performed using Statistical Package for the Social Sciences (SPSS, IBM, USA). Independent sample T-test was performed to compare the mean values of the calcium and phosphate between the conventional 
resin composite (Filtek $^{\mathrm{TM}}$ Z350-XT, 3M ESPE ${ }^{\circledR}$, USA) and (ACTIVA ${ }^{\mathrm{TM}}$ bioactive, Pulpdent, USA) for ion release test and EDX analysis. Independent sample T-test was also used to compare the gap distance measurements between the two groups. The significance level was set at $\mathrm{P} \leq 0.05$.

\section{RESULTS}

\section{Calcium and phosphorous ions release:}

The mean values of $\mathrm{Ca}$ and $\mathrm{P}$ ion release by ICP for both groups after 14 days immersion in distilled water are represented in table (2).

\section{Apatite formation:}

\subsection{SEM Analysis:}

SEM micrographs for the conventional and bioactive restorations' discs after 14 days immersion in phosphate buffer saline are represented in figures $2 \mathrm{a}$. and $2 \mathrm{~b}$. The discs of group I was homogenous with no surface depositions, figure 2a. However, discs of group II; showed white globules on their surfaces, figure $2 \mathrm{~b}$.

\subsection{EDX Analysis:}

The mean values of $\mathrm{Ca}$ and $\mathrm{P}$ elemental analysis via EDX for both groups after 14 days immersion in phosphate buffer saline are represented in table (3).

\subsection{Calcium/Phosphorous Ratio:}

The Calcium/phosphorous ratio is calculated from the $\mathrm{Ca}$ and $\mathrm{P}$ elemental analysis mean values. For conventional resin composite (Filtek ${ }^{\mathrm{TM}}$ Z350$\mathrm{XT}$ ) $\mathrm{Ca} / \mathrm{P}$ was zero while for (ACTIVA ${ }^{\mathrm{TM}}$ bioactive restorative material) $\mathrm{Ca} / \mathrm{P}$ was 1.7 .

TABLE (2): Mean values (ppm) and standard deviations of calcium and phosphorous ion release for conventional resin composite and bioactive restorative material.

\begin{tabular}{|c|c|c|c|}
\hline Group & $\begin{array}{c}\text { Group I } \\
\left.\text { (Filtek }^{\mathrm{TM}} \mathrm{Z} 350-\mathrm{XT}\right) \text { conventional resin } \\
\text { composite }(\mathbf{p p m})\end{array}$ & $\begin{array}{c}\text { Group II } \\
\text { (ACTIVA bioactive) restorative } \\
\text { material }(\mathbf{p p m})\end{array}$ & P value \\
\hline Ca Ion Release & $29.32 \pm 1.62$ & $30.06 \pm 0.98$ & 0.44 \\
\hline P Ion Release & 0 & $1.18 \pm 0.28$ & $0.024 *$ \\
\hline
\end{tabular}

*: significant $(p \leq 0.05)$.

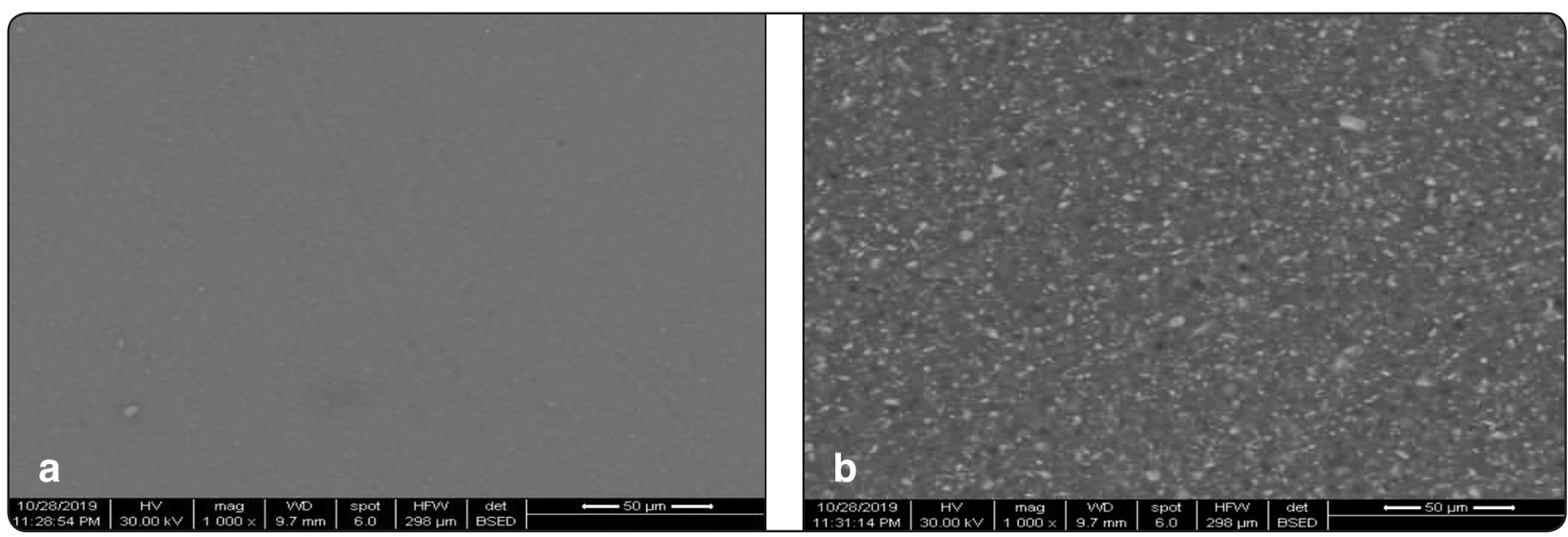

Fig. (2). SEM micrographs for (a) conventional resin composite discs (3M Filtek Z350) and (b) ACTIVA ${ }^{\mathrm{TM}}$ bioactive restorative materials discs after 14 days immersion in phosphate buffer saline, Magnification: 1000x. 
TABLE (3): Mean values and standard deviations of calcium and phosphorous via EDX analysis (atomic \%) for conventional resin composite (Filtek ${ }^{\mathrm{TM}}$ Z350-XT) and ACTIVA ${ }^{\mathrm{TM}}$ bioactive restorative material groups.

\begin{tabular}{|c|c|c|c|}
\hline Test $>$ Group & $\begin{array}{c}\text { Group I (Filtek }{ }^{\mathrm{TM}} \text { Z350-XT) } \\
\text { conventional resin composite (atomic \%) }\end{array}$ & $\begin{array}{l}\text { Group II (ACTIVA }{ }^{\mathrm{TM}} \text { bioactive } \\
\text { restorative material) (atomic \%) }\end{array}$ & Pvalue \\
\hline Ca elemental analysis & $0.2 \pm 0.05$ & $0.72 \pm 0.34$ & 0.151 \\
\hline P elemental analysis & 0 & $0.41 \pm 0.13$ & $0.047 *$ \\
\hline
\end{tabular}

*: significant $(p \leq 0.05)$.
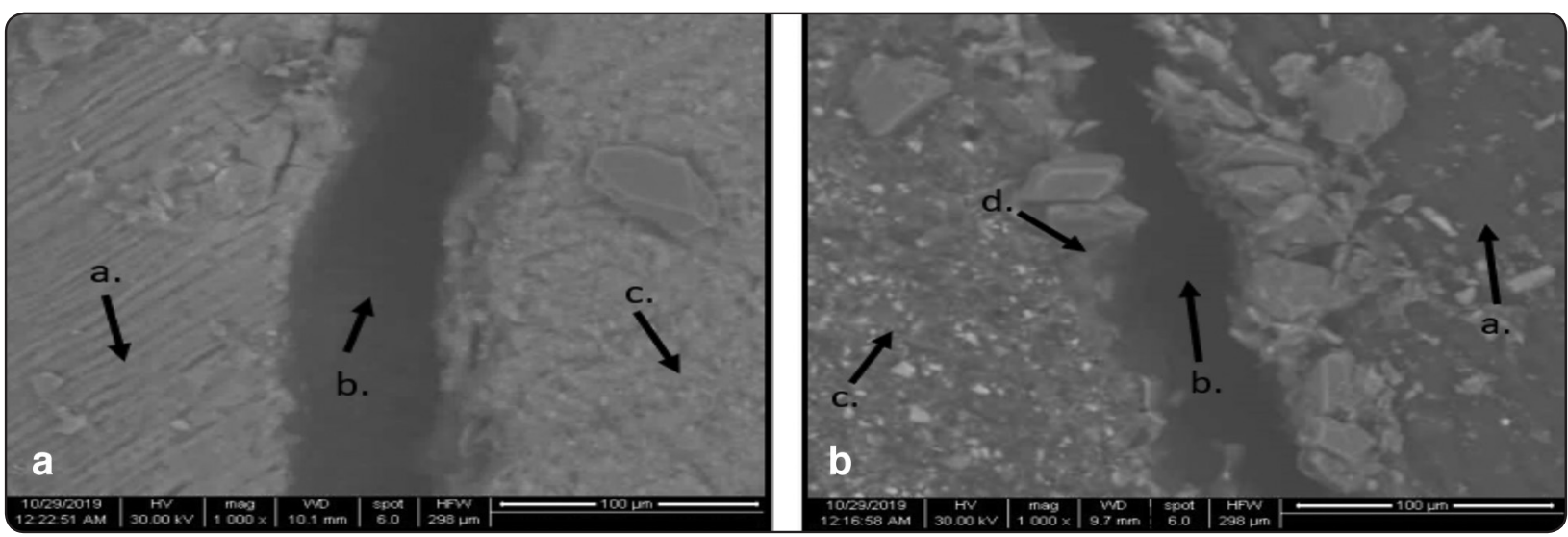

Fig. (3). SEM micrograph for (a) resin composite 3M Filtek Z350-tooth structure interface, a. tooth structure, b. Gap between tooth structure and 3M Filtek Z350, c. 3M Filtek Z350 resin composite. (bv) ACTIVA-tooth structure interface, a. tooth structure, b. Gap between tooth structure and ACTIVA, c. ACTIVA bioactive restoration, d. Apatite layer formation Magnification: 1000x.

\section{Interfacial microscopic examination:}

\section{SEM interfacial microscopic examination:}

Representative SEM micrographs for the interface between teeth and restorations for group I; conventional resin composite 3M Filtek Z350, and group II ACTIVA ${ }^{\mathrm{TM}}$ bioactive restorative material after 14 days immersion in phosphate buffer saline are shown in figures (3a) and (3b) respectively. In group I, gaps were detected between the teeth structure and resin composite restorations with absence of any crystal structure at the interface, figure (3a). In group II although gaps were also detected at the interface, yet crystal-like structure began formation at the borders of the gaps, figure (3b).

\section{Gap distance measurement between teeth and restorations:}

The gap distances mean values are shown in table (4).

TABLE (4): Mean values of gap distances $(\mu \mathrm{m})$ for conventional resin composite (Filtek ${ }^{\mathrm{TM}} \mathrm{Z} 350-\mathrm{XT}$ ) and ACTIVA $^{\mathrm{TM}}$ bioactive restorative material groups.

\begin{tabular}{|l|c|c|c|}
\hline Group & $\begin{array}{c}\text { Group I (Filtek }{ }^{\mathrm{TM}} \text { Z350-XT) } \\
\text { conventional resin composite }(\boldsymbol{\mu} \mathbf{m})\end{array}$ & $\begin{array}{c}\text { Group II (ACTIVA } \\
\text { material) }(\boldsymbol{\mu m})\end{array}$ & P value \\
\hline Gap Distance & $44.14 \pm 12.34$ & $44.39 \pm 5.96$ & $\mathrm{p} \geq 0.5$ \\
\hline
\end{tabular}

$*$ : significant $(p \leq 0.05)$ 


\section{DISCUSSION}

The bioactive restorative material ACTIVA was selected in this research to evaluate its calcium and phosphorous ions releasing property and its claimed bioactivity. It is compared with the resin composite (Filtek $^{\mathrm{TM}}$ Z350-XT) that has no bioactive nature. This offers a reasonable comparison to this bioactive restorative material, thereby allowing practitioners to evaluate the restorative materials prognosis. The remineralization process was generally assessed through ions release determination(Reynolds, 2008). In this study the choice of using distilled water was to ensure the absence of any initial ions in the media to study the release profiles of the materials. As the distilled water is devoid of inorganic 'mineral' content like calcium, phosphorus and magnesium (Thakur et al., 2014).

In this study, after 14 days immersion in distilled water both groups I (control) conventional restorative material $3 \mathrm{M}$ Filtek ${ }^{\mathrm{TM}} \mathrm{Z} 350$ resin composite and group II ACTIVA ${ }^{\mathrm{TM}}$ bioactive restorative material released $\mathrm{Ca}$ ions with no significant difference between them $(29.32 \pm 1.62$ and $30.06 \pm 0.98 \mathrm{ppm}$ respectively) (table 2 ). This finding was in harmony with a previous study performed by (Tiskaya et al.,2019) who showed that both ACTIVA and the bioactive restoration Cention $\mathrm{N}$ (Ivoclar Vivadent, Switzerland) released Ca ions (7 and 60 ppm respectively) when immersed in tris buffer for 6 weeks. There was more Ca release, 240 ppm after six weeks immersion from Cention $\mathrm{N}$, while ACTIVA released 111 ppm Ca into artificial saliva $\mathrm{pH} 4$. Related to the present study, the release of $\mathrm{Ca}$ ions from ACTIVA may be attributed to its bioactive fillers and patented bioactive ionic resin which is responsible for high release and recharge of calcium, and phosphorous. Also, the absence of the Bis-GMA in the composition gave a chance for better ions release. While, the release of $\mathrm{Ca}$ ions from the conventional resin composite $3 \mathrm{M} \mathrm{Filtek}^{\mathrm{TM}}$ Z350 may be attributed to the presence of $\mathrm{Ca}$ in its composition, although the presence of $\mathrm{Ca}$ was not mentioned by the manufacturer.
On the other hand, a significant difference was found between the $\mathrm{P}$ ion release form groups I conventional resin composite $3 \mathrm{M}$ Filtek ${ }^{\mathrm{TM}} \mathrm{Z} 350$ and group II 'ACTIVA' bioactive restorative material'. There was no $\mathrm{P}$ ion release form group I $(0 \mathrm{ppm})$. This may be due to the absence of any $\mathrm{P}$ ions in its composition. On the other hand, group II ACTIVA $^{\mathrm{TM}}$ bioactive restorative material released $\mathrm{P}$ ions $(1.18 \pm 0.28 \mathrm{ppm})$ which may be due to the bioactive fillers and patented bioactive ionic resin.

Whereas to investigate the apatite formation upon the specimens 'surfaces, the discs were immersed in the phosphate buffer saline. Based on a previous study, 14 days was considered sufficient time to indicate the remineralizing potential of the bioactive material (Jang et al., 2018).

The phosphate buffer saline (PBS) was used previously by Parirokh et al. who used it as an immersion media to simulate the human body environment, thus generating more clinically relevant results. This study stored a root-end filling material (Mineral Trioxide Aggregate "MTA") in phosphate buffer saline for three months, resulting in apatite crystals formation over MTA exhibiting a good apical seal and low cytotoxicity. Roots in PBS showed significantly less bacterial penetration; $(39.13 \pm 8.65$ days) compared to roots in saline ( $73.85 \pm 6.52$ days) (Parirokh et al., 2009).

Regarding the present study, after immersion in the phosphate buffer saline for 14 days, using SEM, white globules were detected on the surfaces of ACTIVA discs (figure 2b), while the control specimens showed homogenous surfaces with absences of any white spots (figure 2a). To detect the composition, EDX analysis was performed for the specimens surfaces from both groups. The white globules on ACTIVA discs were composed of $\mathrm{Ca}$ and $\mathrm{P}$. The $\mathrm{Ca} / \mathrm{P}$ ratio was 1.7 which may denote hydroxyapatite crystals.

In harmony with this study results, Garcia and Morrow evaluated the apatite formation and the integration of two bioactive materials ACTIVA ${ }^{\mathrm{TM}}$ 
bioactive restorative (AR) and ACTIVA $^{\mathrm{TM}}$ bioactive base/liner ${ }^{\mathrm{TM}}(\mathrm{AB})$ into dentinal tubules through inspection of surrounding dentinal tubules and the resin tags. Dentin discs were prepared according to manufacturers' instructions with bioactive restorative material and bioactive base/ liner and immersed in phosphate buffered saline at $37^{\circ} \mathrm{C}$ for three, seven, and 30 days. SEM and EDX was utilized to verify hydroxyapatite formation. EDX chemical analysis for $\mathrm{Ca}$ and $\mathrm{P}$ confirmed the hydroxyapatite formation $(\mathrm{Ca} / \mathrm{P}=1.671)$. The $\mathrm{Ca} / \mathrm{P}$ ratio for AR ranged from 2.0-2.5 across dentin, tags, and resin (Garcia-Godoy \& Morrow, 2016).

From a chemical point of view there are several prerequisites that need to be fulfilled for HA to form. There must be a condition of ion saturation toward hydroxyapatite, meaning that the concentration of $\mathrm{Ca}$ and $\mathrm{P}$ should be above the solubility limit for hydroxyapatite. In addition, the $\mathrm{pH}$ needs to be in the correct range. Hydroxyapatite is the most stable compound in the calcium phosphate system at a $\mathrm{pH}$ between 4.2 and 12. Since our immersion media was phosphate buffer saline of $\mathrm{pH}=7.4$, therefore it was considered a suitable environment for apatite formation (Aljabo et al., 2016).

Class V cavities offer a good experiment for testing adaptation of the material to the tooth structure. The cervical lesions pose a restorative challenge due to the complex morphology, where the coronal margin is in enamel and cervical margin in dentin/cementum (Kaushik \& Yadav, 2017). Thus, in the present study class $V$ cavities were selected. Teeth sectioning was performed before storage to avoid apatite layer removal if the sectioning process were done after immersion (Profeta et al., 2012).

For standardization of enamel and dentin structure, in each tooth two cavities were prepared one cavity was restored by the conventional Filtek $^{\mathrm{TM}}$ BulkFill resin composite (Group I), while the other cavity in the same tooth was restored by ACTIVA $^{\mathrm{TM}}$ bioactive restorative material
(Group II). Then sectioning was performed buccolingually through the buccal and lingual restorations of each tooth (Ebaya et al., 2019).

The use of SEM/EDX analysis is a technique that has been employed to detect the formation of apatite containing $\mathrm{Ca}$ and $\mathrm{P}$ on the surface of bioactive materials (Ciobanu et al., 2009).

In the present study, the apatite formation at tooth-restoration interface was evaluated among the different specimens using SEM. Teeth were assessed under SEM at 1000x magnification which showed perfectly the apatite layer deposition compared to other magnifications. Crystal like structure was found at the interface between teeth and ACTIVA restoration (figure 3.b). This morphology is often indicative of hydroxyapatite layer formation sealing a part of the gap between tooth and restoration surfaces (Ciobanu et al., 2009).

This may be attributed to bioactivity of ACTIVA restoration which may stimulate apatite crystal formation at the tooth-restoration interface. This natural remineralizing process might knit the tooth and restoration together, penetrate and fill microgaps and seal margins against microleakage and failure. Yet, elemental analysis at the interface is recommended for confirmation. On the other hand, in group I no crystal structure was detected at the interface (figure 3a), this may be due to the absence of any bioactivity of this material. Although $\mathrm{Ca}$ was assessed to be released from the control group however the absence of any P ions released from the material may hinder the formation of hydroxyapatite.

Regarding the mean values for the gap distance in group I; conventional resin composite (Filtek ${ }^{\mathrm{TM}}$ Z350-XT) and group II; ACTIVA ${ }^{\mathrm{TM}}$ bioactive restorative material after 14 days immersion in phosphate buffer saline were $(44.14 \pm 12.34$ and $44.39 \pm 5.96 \mu \mathrm{m})$ respectively. No significant difference was detected between both groups (table 4). This may be attributed to the short duration (14 days) of immersion in phosphate buffered saline 
which may provide insufficient time for significant closure of the gap by the bioactive material. Jefferies et al. stated that it may take time up to 8 months for the apatite formation to seal artificial marginal gaps in calcium-based bioactive dental cements when immersed in phosphate buffer saline. They also stated that each bioactive material had a specific rate of apatite deposition; it may take up to 35 days immersion in PBS for the calcium aluminate/glass ionomer bioactive cement for marginal reduction while calcium silicate cements (MTA) demonstrated a marginal gap closure with a very rapid rate, and virtually complete gap closure within 24 to 48 hours (Jefferies et al., 2015).

It should be noted that the manufacturer previously recommended in September 2017, the application of a bonding agent only in non-retentive cavity preparations. Yet many studies doubted the longevity of the restoration without using the bonding agent. Consequently, in March 2019, the manufacturer's instructions stated the mandatory use of a bonding agent. The reason may be the poor adhesive ability of the material that is stated in several laboratory and clinical findings (van Dijken et al., 2019)(Benetti et al., 2019) (Sultan et al., 2020). Therefore, the present study used ACTIVA ${ }^{\mathrm{TM}}$ bioactive restorative material with pretreatment by etching and bonding agent. However, there was a concern about the bioactivity of ACTIVA after bonding agent application.

In the current research, although the claimed bioactivity of ACTIVA in depositing hydroxyapatite was observed at tooth-restoration interface, yet no significant effect in gap closure was detected when compared to conventional resin composite (table 4). Thus, long term inspection of this material may be beneficial to investigate its potential for marginal sealing ability by time. In addition, intraoral observation of these restorations when applied in patients' mouth may be recommended.

\section{CONCLUSIONS}

Within the limitations of the present study, it was concluded that:

1. ACTIVA $^{\mathrm{TM}}$ bioactive restorative material showed more phosphorous ions release than Filtek $^{\mathrm{TM}}$ Z350-XT resin composite which seems promising in ions release capability.

2. ACTIVA $^{\mathrm{TM}}$ bioactive restorative material formed white globules on the surfaces of the specimens' discs, while the control specimens showed homogenous surfaces with absences of any white spots, which indicates the ACTIVA ${ }^{\mathrm{TM}}$ bioactive restorative material apatite forming ability.

3. No complete gap closure at the tooth- ACTIVA bioactive restoration interface was detected compared to Filtek ${ }^{\mathrm{TM}} \mathrm{Z} 350-\mathrm{XT}$ resin composite. Complete gap closure may need long term duration inspection.

4. Non-destructive test for investigation of the tooth-restoration interface may be valuable with EDX analysis to indicate the type of the precipitated material at the interface.

\section{REFERENCES}

- $\quad$ Aljabo, A., Neel, E. A. A., Knowles, J. C., \& Young, A. M. (2016). Development of dental composites with reactive fillers that promote precipitation of antibacterial-hydroxyapatite layers. Materials Science and Engineering: C, 60, 285-292.

- Alshammary, R. M. N. (2019). A Measure of Mechanical Properties, Microhardness, and Fluoride Releasing Properties of a New Glass Hybrid Restorative Dental Material. University of California, Los Angeles.

- Badahman, M. H. (2019). Bioactive Materials: Ion Release \& Recharge, Wear, Gloss \& Hydroxyapatite Formation. The University of Alabama at Birmingham.

- $\quad$ Balhaddad, A. A., Kansara, A. A., Hidan, D., Weir, M. D., Xu, H. H. K., \& Melo, M. A. S. (2019). Toward dental caries: Exploring nanoparticle-based platforms and calcium phosphate compounds for dental restorative materials. Bioactive Materials, 4, 43-55. 
- $\quad$ Benetti, A. R., Michou, S., Larsen, L., Peutzfeldt, A., Pallesen, U., \& van Dijken, J. W. V. (2019). Adhesion and marginal adaptation of a claimed bioactive, restorative material. Biomaterial Investigations in Dentistry, 6(1), 90-98.

- Ciobanu, G., Carja, G., Ciobanu, O., Sandu, I., \& Sandu, A. (2009). SEM and EDX studies of bioactive hydroxyapatite coatings on titanium implants. Micron, 40(1), 143-146.

- $\quad$ Ebaya, M. M., Ali, A. I., \& Mahmoud, S. H. (2019). Evaluation of Marginal Adaptation and Microleakage of Three Glass Ionomer-Based Class V Restorations: In Vitro Study. European Journal of Dentistry, 13(04), 599-606.

- Garcia-Godoy, F., \& Morrow, B. R. (2016). Profilometry bioactive dental materials analysis and evaluation of dentin integration. J Dent Res, 95, 1828.

- Jang, J.-H., Lee, M. G., Ferracane, J. L., Davis, H., Bae, H. E., Choi, D., \& Kim, D.-S. (2018). Effect of bioactive glass-containing resin composite on dentin remineralization. Journal of Dentistry, 75, 58-64.

- Jefferies, S. R., Fuller, A. E., \& Boston, D. W. (2015). Preliminary evidence that bioactive cements occlude artificial marginal gaps. Journal of Esthetic and Restorative Dentistry, 27(3), 155-166.

- Kaushik, M., \& Yadav, M. (2017). Marginal microleakage properties of activa bioactive restorative and nanohybrid composite resin using two different adhesives in non carious cervical lesions-an in vitro study. Journal of the West African College of Surgeons, 7(2), 1.

- Odermatt, R., Mohn, D., Wiedemeier, D. B., Attin, T., \& Tauböck, T. T. (2020). Bioactivity and Physico-Chemical Properties of Dental Composites Functionalized with Nano-vs. Micro-Sized Bioactive Glass. Journal of Clinical Medicine, 9(3), 772 .

- Owens, B. M., Phebus, J. G., \& Johnson, W. W. (2018). Evaluation of the marginal integrity of a bioactive restorative material. Gen Dent, 66(03), 32-36.

- $\quad$ Parirokh, M., Askarifard, S., Mansouri, S., Haghdoost, A. A., Raoof, M., \& Torabinejad, M. (2009). Effect of phosphate buffer saline on coronal leakage of mineral trioxide aggregate. Journal of Oral Science, 51(2), 187-191.
- Profeta, A. C., Mannocci, F., Foxton, R. M., Thompson, I., Watson, T. F., \& Sauro, S. (2012). Bioactive effects of a calcium/sodium phosphosilicate on the resin-dentine interface: a microtensile bond strength, scanning electron microscopy, and confocal microscopy study. European Journal of Oral Sciences, 120(4), 353-362.

- Reynolds, E. C. (2008). Calcium phosphate-based remineralization systems: scientific evidence? Australian Dental Journal, 53(3), 268-273.

- $\quad$ Spencer, P., Ye, Q., Misra, A., Goncalves, S. E. de P., \& Laurence, J. S. (2014). Proteins, pathogens, and failure at the composite-tooth interface. Journal of Dental Research, 93(12), 1243-1249.

- $\quad$ Sultan, M., ElKorashy, M., \& Fawzy, A. (2020). Bonding Effectiveness of Bioactive Self-Adhesive Restorative Material to Enamel and Dentin Using Different Bonding Protocols. Egyptian Dental Journal, 66(3-July (Conservative Dentistry \& Endodontics)), 1915-1924.

- Thakur, A. K., Srivastava, N., Chakrabarty, T., Rebary, B., Patidar, R., Sanghavi, R. J., Shahi, V. K., \& Ghosh, P. K. (2014). An improved protocol for electrodialytic desalination yielding mineral-balanced potable water. Desalination, 335(1), 96-101.

- $\quad$ Tiskaya, M., Al-Eesa, N. A., Wong, F. S. L., \& Hill, R. G. (2019). Characterization of the bioactivity of two commercial composites. Dental Materials, 35(12), 1757-1768.

- Vallittu, P. K., Boccaccini, A. R., Hupa, L., \& Watts, D. C. (2018). Bioactive dental materials-Do they exist and what does bioactivity mean? Dental Materials: Official Publication of the Academy of Dental Materials, 34(5), 693.

- $\quad$ van Dijken, J. W. V, Pallesen, U., \& Benetti, A. (2019). A randomized controlled evaluation of posterior resin restorations of an altered resin modified glass-ionomer cement with claimed bioactivity. Dental Materials, 35(2), 335-343.

- Yli-Urpo, H., Närhi, M., \& Närhi, T. (2005). Compound changes and tooth mineralization effects of glass ionomer cements containing bioactive glass (S53P4), an in vivo study. Biomaterials, 26(30), 5934-5941. 